\title{
Efeitos do glyphosate nos teores de lignina, celulose e fibra em Brachiaria decumbens ${ }^{1}$
}

\author{
Glyphosate effects in lignin, cellulose and fiber contents in \\ Brachiaria decumbens
}

\author{
Dana Katia Meschede ${ }^{2 *}$, Edivaldo Domingues Velini ${ }^{3}$, Caio Antonio Carbonari ${ }^{2}$, Maria Lucia \\ Bueno Trindade ${ }^{4}$, Giovanna Larissa Gimenes Cotrick Gomes ${ }^{5}$
}

\begin{abstract}
Resumo - Este trabalho teve como objetivo quantificar os teores de fibra, celulose e lignina, na parte aérea do capim-braquiária (Brachiaria decumbens), submetida à diferentes dosagens de glyphosate. O experimento foi realizado em uma área de pastagem de Brachiaria decumbens, na Fazenda Experimental Lageado, FCA/UNESP, Botucatu/SP. Os tratamentos foram constituído de cinco dosagens de glyphosate $\left(36 ; 72 ; 180 ; 360\right.$ e 720 g e.a. ha $\left.{ }^{-1}\right)$ mais uma testemunha sem aplicação, utilizando-se delineamento em blocos casualizados, com quatro repetições. Para aplicação do herbicida, foi utilizado pulverizador costal pressurizado por $\mathrm{CO}_{2}$, munido de barra de pulverização composta por quatro pontas DG11002 VS, espaçadas de 0,5 m entre si, e com volume de calda de $200 \mathrm{~L} \mathrm{ha}^{-1}$. Em geral, observou-se que os teores de fibra não foram alterados pela aplicação do glyphosate e que todas as dosagens aplicadas promoveram incremento nos teores de celulose, aos 60 dias após aplicação do produto. A aplicação de glyphosate diminuiu significativamente os níveis de lignina a partir de 30 dias após aplicação do produto, melhorando a digestibilidade de Brachiaria decumbens pela redução dos níveis de lignina na planta.
\end{abstract}

Palavras-chave: Digestibilidade, herbicida, capim-braquiária.

\begin{abstract}
This study aimed to quantify the levels of fiber, cellulose and lignin in Brachiaria decumbent dossel, submitted to different doses of glyphosate. The experiment was carried out in a pasture area containing Brachiaria decumbens at Fazenda Experimental Lageado, FCA/UNESP, Botucatu County, São Paulo State. Treatments consisted of five glyphosate doses $\left(36,72,180,360\right.$ and $\left.720 \mathrm{~g} \mathrm{ha}^{-1}\right)$ and an untreated control, by using a randomized complete block design with four replications. For herbicide application, a backpack sprayer pressurized by $\mathrm{CO}_{2}$ and equipped with a spray bar with four nozzles DG11002 VS was used, spaced $0.5 \mathrm{~m}$, with solution volume of $200 \mathrm{~L} \mathrm{ha}^{-1}$. In general, it could be observed that fiber contents were not affected by glyphosate application and that all applied doses promoted increase in cellulose levels, 60 days after application. Glyphosate application reduced levels of lignin from 30 days

\footnotetext{
* Autor para correspondência

${ }^{1}$ Recebido para publicação em 04/01/2011 e aceito10/04/2011.

${ }^{2}$ Engenheiro(a) Agrônomo(a) Dr.(a), FCA/UNESP, Depto. de Produção Vegetal, Faculdade de Ciências Agronômicas - FCA/UNESP, 18603-970, Botucatu-SP, meschede@ fca.unesp.br, carbonari@ fca.unesp.br ${ }^{3}$ Professor Livre-Doente, Depto. de Produção Vegetal, FCA/UNESP, 18603-970, Botucatu-SP, velini@ fca.unesp.br.

${ }^{4}$ Pesquisadora Dra. Biocompostos, mlbtrindade@uol.com.br

5 .Doutoranda em Agronomia, FCA/UNESP, Depto. de Produção Vegetal, FCA/UNESP, 18603-970, Botucatu-SP, giovanna.gomes@fca.unesp.br.
} 
after herbicide application, improving Brachiaria decumbens digestibility by reducing levels of lignin in plant.

Key words: Digestibility, herbicide, signal grass.

A área ocupada pelas pastagens ocupa uma posição de destaque no cenário agrícola nacional. Estimativas admitem que $80 \%$ a $90 \%$ das áreas de pastagens no País são constituídas por capins do gênero Brachiaria, e que a $B$. decumbens ocupa mais de $50 \%$ do total formado por essas gramíneas (Boddey et al., 2004).

A produtividade animal em pastagem resulta da interação entre os estádios de crescimento da planta forrageira, condições do meio, utilização da forragem produzida e conversão em produto animal (Hodgson, 1990). Segundo Van Soest (1965), o teor de fibras é um dos fatores mais limitante do consumo de volumosos, sendo que os valores dos constituintes da parede celular superiores a $55-60 \%$ na matéria seca correlacionam-se de forma negativa com o consumo de forragem.

A lignina, um polímero nãocarboidrato, composto de monômeros fenólicos (do tipo fenilpropano), é reconhecidamente um dos principais componentes responsáveis pela queda da digestibilidade dos nutrientes das plantas forrageiras (Dehority \& Johnson, 1961; Hartley \& Jones, 1977; Morrison, 1983, Jung \& Vogel, 1986; Van Soest, 1994), e tem sido justamente por esta razão, útil na estimativa da extensão da digestão da fibra (Barton II \& Akin, 1977). Análises laboratoriais de plantas forrageiras são necessárias para estimar a qualidade nutritiva e, conseqüentemente, predizer a extensão da degradação biológica (Van Soest \& Robertson, 1980).

A lignina é uma molécula fenólica altamente complexa e que só é menos abundante em plantas do que a celulose. A estrutura da lignina ainda não é completamente conhecida, mas sua presença é fundamental para a rigidez das células e tecidos e na resistência a estresses bióticos a abióticos (Raes et al., 2003; Cabané et al., 2004; Taiz \& Zeiger, 2009). Juntamente com a celulose e hemicelulose, a lignina é um dos principais constituintes da planta, sendo responsável pela sua resistência. É um biopolímero aromático amorfo, tridimencional, formado via polimerização oxidativa, que ocorre na parede celular de plantas superiores em diferentes composições, como por exemplo, em madeiras duras de 25 a $35 \%$, madeiras macias de 18 a $25 \%$ e gramíneas de 10 a 30\% (Bononi, 1999; Hilden, 2000).

A redução da síntese de lignina pode acontecer através do uso de um inibidor da rota do ácido chiquímico, mais especificamente da enzima 5enolpiruvilchiquimato 3-fosfato sintase (EPSPs), ou seja, pela aplicação do herbicida glyphosate. Esta enzima é fundamental para produção de aminoácidos aromáticos e de todos os compostos fenólicos em plantas, incluindo os monômeros da lignina.

A correta quantificação de lignina em capim-braquiária é uma importante ferramenta para avaliação nutricional da pastagem, pela melhoria da digestibilidade da planta. Sendo assim, este trabalho teve por objetivo verificar os teores de fibra, celulose e lignina em plantas de $B$. decumbens submetida à diferentes dosagens de glyphosate, em condições de campo.

$\mathrm{O}$ experimento foi conduzido na Fazenda Experimental Lageado, pertencente a Faculdade de Ciências Agronômicas FCA/UNESP, no município de Botucatu/SP em uma área de pastagem de $B$. decumbens já estabelecida, com 8 anos de idade em estádio vegetativo. 
As parcelas experimentais apresentaram cinco metros de comprimento e quatro metros de largura totalizando área útil de $20 \mathrm{~m}^{2}$. Foram utilizados seis tratamentos, dos quais cinco deles eram de glyphosate nas dosagens de $36 ; 72 ; 180 ; 360$ e 720 g e.a. ha ${ }^{-1}$ e uma testemunha sem aplicação do herbicida. Para os tratamentos com o glyphosate foi utilizado $o$ produto comercial Roundup Original $^{\circledR}\left(360\right.$ g e.a. $\left.\mathrm{L}^{-1}\right)$. O delineamento experimental utilizado foi o de blocos casualizados com quatro repetições, sendo as parcelas foram constituídas de $20 \mathrm{~m}^{2}(5 \mathrm{~m} \mathrm{x}$ $4 \mathrm{~m})$, e área útil de $12 \mathrm{~m}^{2}$.

A aplicação do glyphosate foi realizada utilizando-se um pulverizador costal pressurizado a $\mathrm{CO}_{2}$, em pressão constante de 2 bar, com reservatório com capacidade para $2 \mathrm{~L}$ de calda, conectado a uma barra equipada com quatro pontas de pulverização DG11002 VS, espaçadas em $50 \mathrm{~cm}$ entre si e com velocidade de deslocamento de $1 \mathrm{~m} \mathrm{~s}^{-1}$, proporcionando consumo de calda de $200 \mathrm{~L} \mathrm{ha}^{-1}$.

As avaliações foram realizadas aos $30 \mathrm{e}$ 60 dias após a aplicação do glyphosate. Para tanto, as plantas foram cortadas rente ao chão, em uma área útil de $1 \mathrm{~m}^{2}$ por parcela. A área útil foi determinada aleatoriamente em cada parcela e delimitada por um quadro de madeira. As plantas de $B$. decumbens coletadas em cada parcela foram acondicionadas em sacos de papel, depois secas em estufa de circulação forçada de ar a $65^{\circ} \mathrm{C}$ até adquirir peso constante. Posteriormente, as amostras foram moídas em moinhos de rotor circular com facas (Marconi MA340) e em seguida submetidas às análises de teores de lignina, celulose e fibra. A técnica utilizada foi baseada no método da lignina em detergente ácido (LDA), onde a amostra é previamente tratada com solução de detergente ácido, resultando na fibra em detergente ácido (FDA), que em seguida submetida à digestão com solução de ácido sulfúrico a $72 \%$ (Van Soest, 1965). No entanto, esta técnica foi adaptada com a utilização de saquinhos confeccionados em TNT 100 porosidade de 100 micra. Após a digestão os saquinhos foram colocados em autoclave $\left(120^{\circ} \mathrm{C}\right.$ por 30 minutos), dispostos no interior de garrafão para solução de capacidade de $20 \mathrm{~L}$, contendo $50 \mathrm{~mL}$ de solução em detergente ácido por amostra. Em seguida, receberam pré-lavagem com água fria para retirada do excesso de detergente, foram submetidos a cinco enxágües com água destilada quente (5 minutos), sendo então, escorridos e imersos em acetona (5 minutos) e secos em estufa $\left(105^{\circ} \mathrm{C}\right)$, de acordo com Lanes et al. (2006).

Os resultados foram submetidos à análise de variância pelo teste $\mathrm{F}$ e as médias foram comparadas pelo teste $\mathrm{t}$ a $5 \%$ de probabilidade.

$\mathrm{Na}$ Tabela 1 encontram-se os teores de fibra em detergente ácido encontrados na $B$. decumbens, aos 30 e 60 dias após aplicação dos tratamentos. Observa-se que os teores de fibra das plantas não foram alterados pela aplicação do glyphosate. Segundo Ferreira et al. (2000), o teor de fibra tem sido utilizado como índice negativo de qualidade, uma vez que representa a fração menos digestível dos alimentos para os ruminantes. A fração fibrosa dilui a energia do alimento e reduz o consumo voluntário, pelo efeito do enchimento ruminal e pela saturação da capacidade de ruminação do animal. Para os teores de celulose (Tabela 2) encontrados na $B$. decumbens, aos 30 dias após aplicação dos tratamentos, verifica-se que a celulose não foi alterada pela aplicação do glyphosate. No entanto, aos 60 dias após aplicação do produto, os níveis de celulose tiveram um aumento significativo pela aplicação das diferentes doses de glyphosate em relação ao tratamento testemunha (Tabela 2). A celulose é o composto químico orgânico que existe em maior abundância nas plantas e em toda a superfície terrestre, é aproveitada pelos ruminantes em diferentes graus, com valores que oscilam desde $20 \%$ até $90 \%$, e 
pode suprir as deficiências energéticas destes animais (Souza \& Santos, 2002).

Tabela 1. Conteúdo de fibra em detergente ácido (\%) em Brachiaria decumbens, 30 e 60 dias após aplicação de glyphosate.

\begin{tabular}{ccc}
\hline Tratamentos & \multicolumn{2}{c}{ Dias após aplicação } \\
\cline { 2 - 3 }$\left(\right.$ g e.a. de glyphosate $\left.\mathrm{ha}^{-1}\right)$ & 30 & $\mathbf{6 0}$ \\
\hline 36 & 40,5 & 46,2 \\
72 & 43,8 & 43,5 \\
180 & 41,3 & 36,5 \\
360 & 45,8 & 42,8 \\
720 & 40,8 & 44,5 \\
Testemunha & 42,5 & 41,8 \\
\hline F tratamento & $0,286^{\mathrm{ns}}$ & $2,428^{\mathrm{ns}}$ \\
F bloco & $0,654^{\mathrm{ns}}$ & $2,983^{\mathrm{ns}}$ \\
C.V. $(\%)$ & 17,93 & 10,07 \\
D.M.S. & 17,47 & 9,84 \\
\hline
\end{tabular}

Médias seguidas de mesma letra, na coluna, não diferem significativamente entre si pelo teste $\mathrm{t}$ ao nível de $5 \%$ de probabilidade.

Tabela 2. Conteúdo de celulose (\%) em plantas de Brachiaria decumbens aos 30 e 60 dias após a aplicação de diferentes dosagens de glyphosate.

\begin{tabular}{lcc}
\hline \multirow{2}{*}{$\begin{array}{c}\text { Tratamentos } \\
\left(\text { g e.a. de glyphosate } \mathrm{ha}^{-1}\right)\end{array}$} & \multicolumn{2}{c}{ Dias após aplicação } \\
\cline { 2 - 3 } & 30 & 60 \\
72 & $32,3 \mathrm{a}$ & $42,3 \mathrm{a}$ \\
180 & $35,5 \mathrm{a}$ & $35,9 \mathrm{ab}$ \\
360 & $43,1 \mathrm{a}$ & $36,9 \mathrm{ab}$ \\
720 & $33,7 \mathrm{a}$ & $32,2 \mathrm{ab}$ \\
$\quad$ Testemunha & $41,0 \mathrm{a}$ & $33,6 \mathrm{ab}$ \\
\hdashline F tratamento & $34,3 \mathrm{a}$ & $33,2 \mathrm{~b}$ \\
F bloco & $1,23^{\mathrm{ns}}$ & $1,91^{\mathrm{n}}$ \\
C.V. $(\%)$ & $0,54^{\mathrm{ns}}$ & $0,98^{\mathrm{ns}}$ \\
D.M.S. & 21,35 & 16,84 \\
\hline
\end{tabular}

Médias seguidas de mesma letra, na coluna, não diferem significativamente entre si pelo teste $\mathrm{t}$ ao nível de $5 \%$ de probabilidade.

A análise do conteúdo de lignina (Tabela 3). Observa-se que aos 60 DAA realizada aos 30 dias após aplicação de glyphosate, revela que os valores se encontram dentro dos níveis encontrados na literatura, e tiveram seus teores reduzidos em mais de $40 \%$ com aplicação de glyphosate, quando comparado com a testemunha. que aplicação de doses subletais de glyphosate influenciaram nos teores de lignina na planta 
Tabela 3. Conteúdo de lignina (\%) em Brachiaria decumbens, 30 e 60 dias após aplicação de glyphosate - Botucatu-SP, 2007.

\begin{tabular}{|c|c|c|}
\hline \multirow{2}{*}{$\begin{array}{c}\text { Tratamentos } \\
\left(\text { g e.a. de glyphosate } \text { ha }^{-1}\right)\end{array}$} & \multicolumn{2}{|c|}{ Dias após aplicação } \\
\hline & 30 & 60 \\
\hline 36 & $13,70 \mathrm{~b}$ & $14,40 \mathrm{ab}$ \\
\hline 72 & $13,35 \mathrm{~b}$ & $15,60 \mathrm{ab}$ \\
\hline 180 & $13,78 \mathrm{~b}$ & $14,00 \mathrm{~b}$ \\
\hline 360 & $13,27 \mathrm{~b}$ & $13,10 \mathrm{~b}$ \\
\hline 720 & $24,23 \mathrm{a}$ & 24,96 a \\
\hline Testemunha & $24,54 \mathrm{a}$ & $26,11 \mathrm{a}$ \\
\hline F tratamento & $3,22^{*}$ & $3,63^{*}$ \\
\hline F bloco & $1,81 \mathrm{~ns}$ & $1,53 \mathrm{~ns}$ \\
\hline C.V. (\%) & 14,25 & 20,42 \\
\hline D.M.S. & 8,20 & 11,70 \\
\hline
\end{tabular}

Médias seguidas de mesma letra, na coluna, não diferem significativamente entre si pelo teste $\mathrm{t}$ ao nível de $5 \%$ de probabilidade.

Os valores de lignina apresentaram reduções significativas, sendo que o pico de redução foi observado nas doses de 180 e $360 \mathrm{~g}$ e.a. ha ${ }^{-1}$, onde o glyphosate reduziu mais de $40 \%$ os níveis de lignina em relação à testemunha. Doses elevadas (720 g.e.a, que representa a dose comercial do produto) não altera os teores de ligninas, provavelmente por que ela já causa efeito de herbicida e não de regulador de crescimento $\mathrm{O}$ glyphosate é o principal herbicida que afeta diretamente a síntese de compostos secundários (Devine et al., 1993), sendo que esse herbicida não seletivo bloqueia a rota do ácido shiquímico pela inibição da enzima EPSPs. A inibição da EPSPs reduz a disponibilidade de aminoácidos aromáticos (triptofano, fenilalanina e tirosina), e ocasiona formação de ácido cinâmico e seus derivados, inibindo, desse modo, a produção de ácidos hidroxifenólicos, de flavonóides e de compostos fenólicos mais complexos, como a lignina (Weaver \& Herrmann, 1997).
A lignina, além das funções inerentes à fisiologia das plantas, apresenta-se como uma barreira de defesa física e química, dificultando a penetração de microrganismos fitopatogênicos (Davis \& Hahlbrock, 1987), consumo por insetos (Coley, 1988), protegendo as plantas contra os fatores bióticos e abióticos, advindos do ambiente. Tais funções justificamse por ser encontrada principalmente na parede celular e na lamela média de células xilemáticas e de outras partes de diferentes origens citológicas, tais como: folha, caule, casca e raízes (Firmino et al., 2006). No entanto, a proporção deste biopolímero faz parte da fração indigestível das plantas utilizadas para alimentação animal (Minson, 1990) e reduções nos teores de lignina das plantas de $B$. decumbens representam um ganho na qualidade desta forrageira.

Em geral, observou-se que os teores de fibra não foram alterados pela aplicação do glyphosate e que todas as doses aplicadas promoveram incremento nos teores de 
celulose, aos 60 dias após aplicação do produto. A aplicação de glyphosate diminuiu significativamente os níveis de lignina a partir de 30 dias após aplicação do produto, melhorando a digestibilidade de Brachiaria decumbens pela redução dos níveis de lignina na planta.

\section{Referências}

BARTON II, F.E.; AKIN, D.E. Digestibility of delignified forage cell walls. Journal of Agricultural and Food Chemistry, v.25, n.6, p.1299-1303, 1977.

BODDEY, R.M. et al. Nitrogen cycling in Brachiaria pastures: the key to understanding the process of pasture decline. Agriculture, Ecosystems and Environment, v.103, n.2, p.389-403, 2004.

BONONI, V.L.R. Zigomicetos, Basidiomicetos e Deuteromicetos: noções básicas de taxonomia e aplicações biotecnológicas. São Paulo: Instituto de Botânica, Secretaria do Meio Ambiente, 1999. $184 \mathrm{p}$.

CABANÉ, M. et al. Condensed lignins are synthesized in poplar leaves exposed to ozone. Plant Physiology, v.134, n.2, p.586-594, 2004.

COLEY, P.D. Effects of plant growth rate and leaf lifetime on the amount and type of antiherbivore defense. Oecologia. v.74, n.4, p. 531-536, 1988.

DAVIS, K. R.; HAHLBROCK, K. Induction of defense responses in cultured parsley cells by plant cell wall fragments. Plant Physiology, v.84, n.4, p.1286-1290, 1987.

DEHORITY, B.A.; JOHNSON, R.R. Effect of particle size upon the in vitro cellulose digestibility of forages by rumen bacteria. Journal of Dairy Science, v.44, n.12, p.22422249, 1961.
DEVINE, M.; DUKE, S.O.; FEDTKE, C. Oxygen toxicity and herbicidal action; secondary physiological effects of herbicides. In: Physiology of herbicide action. New Jersey: Prentice-Hall, p.177-188, 1993.

FERREIRA, M.A. et al. Associação da palma forrageira (Opuntia fícus indica Mill) com diferentes fontes de fibra na alimentação de vacas 5/8 Holandês/Zebu em lactação. Revista Brasileira de Zootecnia, v.29, n.7, p.21282134, 2000.

FIRMINO, A. et al . Alterações lignoanatômicas em Solanum gilo Raddi por aplicação de cálcio e boro como estratégia de defesa. Ciência e Agrotecnologia, v. 30, n. 3, p.394-401, 2006.

HARTLEY, R.D.; JONES, E.C. Phenolic components and degradability of cell walls of grass and legume species. Phytochemistry, v.16, n.10, p.1531-1534, 1977.

HILDEN, L. et al. Do the extracellular enzymes cellobiose dehydrogenase and manganese peroxidase form a pathway in lignin biodegradation?. FEBS Letters, v.477, n.1, p.79-83, 2000.

HODGSON, J. Grazing management: science into practice. United Kingdom: Longman Scientific and Technical, 1990. 203 p.

LANES, E.C.M. Comparação de metodologias para determinação da concentração de fibra em detergente ácido em silagens de milho. Resumos - XXIX Semana de Biologia e XII Mostra de Produção Científica - UFJF, 2006.

JUNG, H.G.; VOGEL, K.P. Methods for simultaneous control of lignin content and composition, and cellulose content in plants. Journal of Animal Science. v.62, n.6, p.1703$1712,1986$.

MORRISON, J.P.E. Proceedings of the Biological Society of Washington Western Atlantic v.83, p.545-568. 1983. 
MINSON D.J. Forage in Ruminant

Nutrition. Academic Press, San Diego, 1990.

RAES, J. et al. Genome-wide characterization of the lignifications toolbox in Arabidopsis. Plant Physiology, v.133, n.3, p.1051-1071, 2003.

RUUHOLA, T.; JULKINEN-TITO, R. Tradeoff between sinthesys of salicylicates and growth of micropropagated Salix pentandra. Journal of chemical Ecology, v.29, n.7, p.1565-1588, 2003.

SOUZA, O.; SANTOS, I.E. Aproveitamento do bagaço de cana-de-açúcar pelos ruminantes. Ministério da Agricultura, Pecuária e Abastecimento, 2002. 3p.

TAIZ, L.; ZEIGER, E. Fisiologia Vegetal. 4 ed. Porto Alegre: Artmed, 2009. 719p.

VAN SOEST, P.J. Symposiun on factors influencing the voluntary intake of herbage by ruminants: voluntary intake relation to chemical composition and digestibility. Journal of Animal Science, v.24, n.3, p.834844, 1965.

VAN SOEST, P.J.; ROBERTSON, J.B. Systems of analysis for evaluating fibrous feeds. In: PIDGEN, W.J.; BALCH, C.C.; GRAHAM, M. (Eds.). Standardization of analytical methodology for feeds. Ottawa: International Development Research Centre, 1980. p.49-60.

VAN SOEST, P.J. Nutritional ecology of the ruminant. 2. ed. Ithaca, NY: Cornell Univ. Press, 1994.

WEAVER, L.M.; HERRMANN, K.M. Dynamics of the shikimate pathway in plants. Trends in Plant Science, v.2, n.9, p.346-351, 1997. 